\title{
Groundwater Diffuse Recharge and its Response to Climate Changes in Semi-Arid Northwestern China
}

\author{
Lin Deng ${ }^{1,2, *}$, Wenke Wang ${ }^{1}$, Yanjun Cai ${ }^{2,3}$, Anyan $\mathrm{Hu}^{1}$, and Liangcheng Tan ${ }^{2}$ \\ ${ }^{1}$ Key Laboratory of Subsurface Hydrology and Ecology in Arid Areas (Ministry of Education), School of Environmental Science \\ and Engineering, Chang'an University, Xi'an, China \\ ${ }^{2}$ State Key Laboratory of Loess and Quaternary Geology, Institute of Earth Environment, Chinese Academy of Sciences, \\ Xi'an, China \\ ${ }^{3}$ Institute of Global Environmental Change, Xi' an Jiaotong University, Xi'an, China
}

Received 26 November 2014, revised 11 February 2015, accepted 18 March 2015

\begin{abstract}
Understanding the processes and rates of groundwater recharge in arid and semi-arid areas is crucial for utilizing and managing groundwater resources sustainably. We obtained three chloride profiles of the unsaturated-zone in the desert/loess transition zone of northwestern China and reconstructed the groundwater recharge variations over the last 11,21, and 37 years, respectively, using the generalized chloride mass balance (GCMB) method. The average recharge rates were 43.7, 43.5, and $45.1 \mathrm{~mm} \mathrm{yr}{ }^{-1}$, respectively, which are similar to those evaluated by the chloride mass balance (CMB) or GCMB methods in other semi-arid regions. The results indicate that the annual recharge rates were not in complete linear proportion to the corresponding annual precipitations, although both exhibited descending tendencies on the whole. Comparisons between the daily precipitation aggregate at different intensity and recharge rates reveal that the occurrence of relatively heavy daily precipitation per year may contribute to such nonlinearity between annual precipitation and recharge. The possible influences of vegetation cover alterations following precipitation change cannot be excluded as well. The approximately negative correlation between the average annual recharge and temperature suggests that changes in temperature have had significant influences on recharge.
\end{abstract}

Key words: Groundwater recharge, Chloride, Unsaturated zone, Semi-arid area, Climate change, Northwestern China

Citation: Deng, L., W. Wang, Y. Cai, A. Hu, and L. Tan, 2015: Groundwater diffuse recharge and its response to climate changes in semi-arid northwestern China. Terr. Atmos. Ocean. Sci., 26, 451-461, doi: 10.3319/TAO.2015.03.18.01(Hy)

\section{INTRODUCTION}

Groundwater is very important to human survival and development, especially in arid and semi-arid areas where the surface water is insufficient. It is vital to understand the processes and rates of groundwater recharge to utilize and manage groundwater resources sustainably. In arid and semi-arid regions unsaturated zones have been recognized as possible sources that retain information on such relations (Stone 1992; De Vries et al. 2000; Gates et al. 2008). This is because water flow is slow and mixing processes are often small in arid and semi-arid environment unsaturated zones. Furthermore, diffuse recharge, which is defined by De Vries and Simmers (2002) as the recharge derived from precipita-

\footnotetext{
* Corresponding author

E-mail:deng_lin@hotmail.com
}

tion that infiltrates vertically from the surface directly into the aquifer, may be the dominant recharge process, playing a vital role in the groundwater budget despite its infrequent occurrence in arid and semi-arid climates (Wang et al. 2008; $\mathrm{Ng}$ et al. 2009).

Distinct unsaturated zone geochemical profiles relating to water transport may be preserved as a result of high evapotranspiration in arid and semi-arid regions (Ginn and Murphy 1997; Edmunds and Tyler 2002). Among the geochemical tracers in arid and semi-arid region unsaturated zones, chloride has been the most widely employed chemical marker (Scanlon et al. 2006). The chloride mass balance (CMB) technique was usually used to estimate diffuse recharge in the past (e.g., Allison and Hughes 1978; Scanlon 1991; Edmunds and Gaye 1994; Bromley et al. 1997; Ng et al. 2009; Scanlon et al. 2010). As part of regional hydrological cycles 
groundwater is under the control of the local climate (Chen et al. 2004; Ali et al. 2012) and changes in climate may alter the recharge process and subsequently impact groundwater resources (Jyrkama and Sykes 2007). The chloride profile in the unsaturated zone can also be used to reveal the palaeoclimate changes. Palaeoclimate and palaeohydrology archives at different time scales have been achieved from vadose-zone chloride profiles in arid and semi-arid areas around the world (Edmunds and Walton 1980; Cook et al. 1992; Tyler et al. 1996; Gates et al. 2008). For example, using the CMB method, Cook et al. (1992) reconstructed the history of unsaturated zone recharge over the past 400-year at northern Senegal, which can be matched with the rainfall and lake level records, implying that the chloride profile can be used to infer the palaeoclimate variations.

In the past several decades great advances have been made in CMB method application, including methodologies and analytical techniques. For instance, the generalized chloride mass balance (GCMB) method was developed based on the conventional CMB method (Murphy et al. 1996; Ginn and Murphy 1997). In the GCMB technique both water and chloride transient fluxes over the land surface are considered. This may effectively promote resolution in climatic reconstruction and investigation of the relationship between precipitation and recharge over long time scales (Edmunds and Tyler 2002), although the lack of information on transient fluxes in most time scales during which the recharge history was kept in chloride profiles in arid areas has restricted its application. For example, comparisons between chloride profiles and such instrumental records as rainfall, river flow have been made in studies in Senegal and Cyprus (Edmunds and Walton 1980; Cook et al. 1992; Edmunds et al. 1992). Ginn and Murphy (1997) applied the GCMB method to data from the Cyprus chloride profile presented by Cook et al. (1992) and gave a brief analysis on the relationship between annual precipitation and recharge rates over 18 years. $\mathrm{Ng}$ et al. (2009) combined chloride-based recharge estimates and numerical model predictions to identify the mechanisms controlling diffuse recharge and achieve recharge history at interannual timescales, in spite of the fact that this approach requires a great variety of parameters that are unavailable for modeling in many cases.

Although the CMB and GCMB methods are applicable to both arid and semi-arid areas, more temporally detailed and time-segregated recharge history can be obtained from chloride profiles in semi-arid climate using these methods. In arid climates the groundwater recharge is usually low. It causes the timescales corresponding to the sampling intervals to be highly compressed (Ginn and Murphy 1997). In semi-arid climates, however, the recharge rates are much higher and the same sampling intervals represent much shorter timescales. Therefore, some recharge records in semi-arid areas may span relatively short time scales during which some instrumental records are available.
In China the CMB method has recently been applied to estimate the net infiltration and recharge in some studies (Lin and Wei 2001; Wang et al. 2006; Liu et al. 2009; Huang and Pang 2011; Lin et al. 2013). Additionally, several studies estimated past recharge rates and also reconstructed palaeoclimate changes using this method (Chen et al. 2001; Ma and Edmunds 2006; Gates et al. 2008; Ma et al. 2009), providing important information on the changes in the local hydrology and climate change over the past hundreds to thousands of years at the studied sites. Palaeohydrology and palaeoclimate archives from unsaturated zones in typically semi-arid areas of north-central China have not been reported. Here, we present three chloride profiles from a desert-loess transition zone, north-central China and use the GCMB method to characterize the recharge history. Comparing the results to meteorological records we also discuss the relationship between diffuse recharge and such climatic variables as precipitation and temperature. This study may provide valuable information for better understanding of the mechanisms controlling diffuse recharge and sustainable use of groundwater in this area.

\section{PHYSICAL GEOGRAPHY AND LOCAL CLIMATE OF THE STUDY AREA}

The desert-loess transition zone of China, located southeast of the Ordos Plateau and to the northwest of the Loess Plateau in north-central China (Fig. 1), is defined as a transitional zone between the desert and loess. In this region the

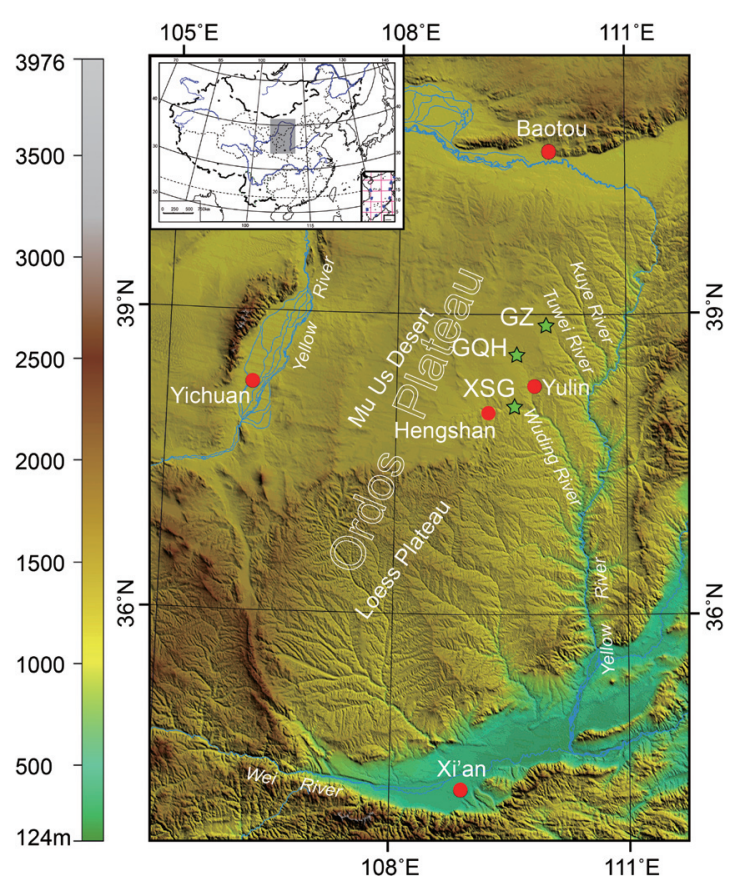

Fig. 1. Locations of the study area and sample sites. Town shown with red round symbols, and sample sites of Gou-zhang (GZ), Ge-qiu-he $(\mathrm{GQH})$, and Xia-sha-gou (XSG) shown with green star symbols. 
eolian sand and loess are distributed alternatively in space but also in time due to Asian monsoon fluctuations. Geomorphologic units include desert land, undulating loess hills called loess 'Liang' and loess 'Mao', grassland covered by sand, highland among lakes, and river valleys and terraces (Zhang et al. 2003). With annual precipitation of 200 - $400 \mathrm{~mm}$ and potential evaporation of $1800-2200 \mathrm{~mm} \mathrm{yr}^{-1}$, it is a typically semi-arid continental monsoon climate. Influenced strongly by the East Asian summer monsoon, more than $75 \%$ of the annual precipitation occurs from July to September, most of which is in the form of storms. With a vulnerable eco-environment there are strong links between climate and hydrological processes.

As one of the most typical parts of the desert-loess transition zone in China, the study region is bounded by the $\mathrm{Mu}$ Us Desert to the north and the Loess Plateau in Shaanxi Province to the south. The water supply there relies largely on groundwater as a result of surface water shortage. The development of coal and crude oil on large scales in recent years has intensified such dependence. The shallow groundwater in the aquifer is recharged mainly by meteoric precipitation (Wang et al. 2008; Hou et al. 2009). Regional recharge has been estimated on large spatial scales using groundwater based approaches in the area (Wang et al. 2008; Yin et al. 2010). However, local recharge estimation based on unsaturated zones in the area has rarely been reported. Although a study has focused on precipitation infiltration and soil moisture variation in the study area for evaluating vegetation water uptake through physical experiments (Yuan et al. 2008), local recharge estimation using the geochemical tracing method and the corresponding hydro-climate record have not yet been obtained. The unsaturated zones exceed- ing $10 \mathrm{~m}$ in depth in this region may afford good archives for recharge history reconstruction with relatively higher resolution using the GCMB method.

\section{FIELD SAMPLING, LITHOLOGY, AND LABORATORY ANALYSES}

Three natural ecosystem unsaturated zone cores were drilled in May 2008 in the desert land of the aforementioned transition zone in Shaanxi Province (Fig. 1). Cores were drilled using a hollow-stem hand auger with $1.5 / 1.0 \mathrm{~m}$ interchangeable steel rods and 90 -mm-diameter opening. The first core was taken from Xia-sha-gou (XSG) village, close to the Heng-shan County seat $\left(109^{\circ} 32^{\prime} \mathrm{E}\right.$, 38 $04^{\circ} \mathrm{N}$, referred to as XSG profile afterwards). The second core was taken from Gou-zhang (GZ) village, Shenmu County (10957'E, $38^{\circ} 53^{\prime} \mathrm{N}$, referred to as $\mathrm{GZ}$ profile afterwards), and the third taken from Ge-qiu-he $(\mathrm{GQH})$ village, close to Yulin City (109³4'E, 38 $36^{\prime} \mathrm{N}$, referred to as GQH profile afterwards).

The XSG profile is $9 \mathrm{~m}$ in depth. The top layer $(3.8 \mathrm{~m})$ is composed of brown fine sand with plant roots in the top $2 \mathrm{~m}$. The second layer $(3.8-5 \mathrm{~m})$ is brown silt. The third layer $(5.0-6.2 \mathrm{~m})$ is brown fine sand, followed with brown silt in the fourth layer (6.2 - $7.2 \mathrm{~m})$, and yellowish-brown silt interbedded with thin yellowish-green fine sand layers in the fifth layer (7.2 - $9.0 \mathrm{~m}$ ) (Fig. 2). The GZ profile is about $8.4 \mathrm{~m}$ in depth. It is composed of homogeneous fine sand. Plant roots can be found within the $2 \mathrm{~m}$ top layer (Fig. 2). The $\mathrm{GQH}$ profile is about $17 \mathrm{~m}$ in depth. The top $7 \mathrm{~m}$ is composed of yellowish-brown fine sand with visible plant roots in the top $1.2 \mathrm{~m}$. From 7.0 - $17 \mathrm{~m}$ is multiple interbedded brown fine sand and brown silt (Fig. 2). No agricultural activity is
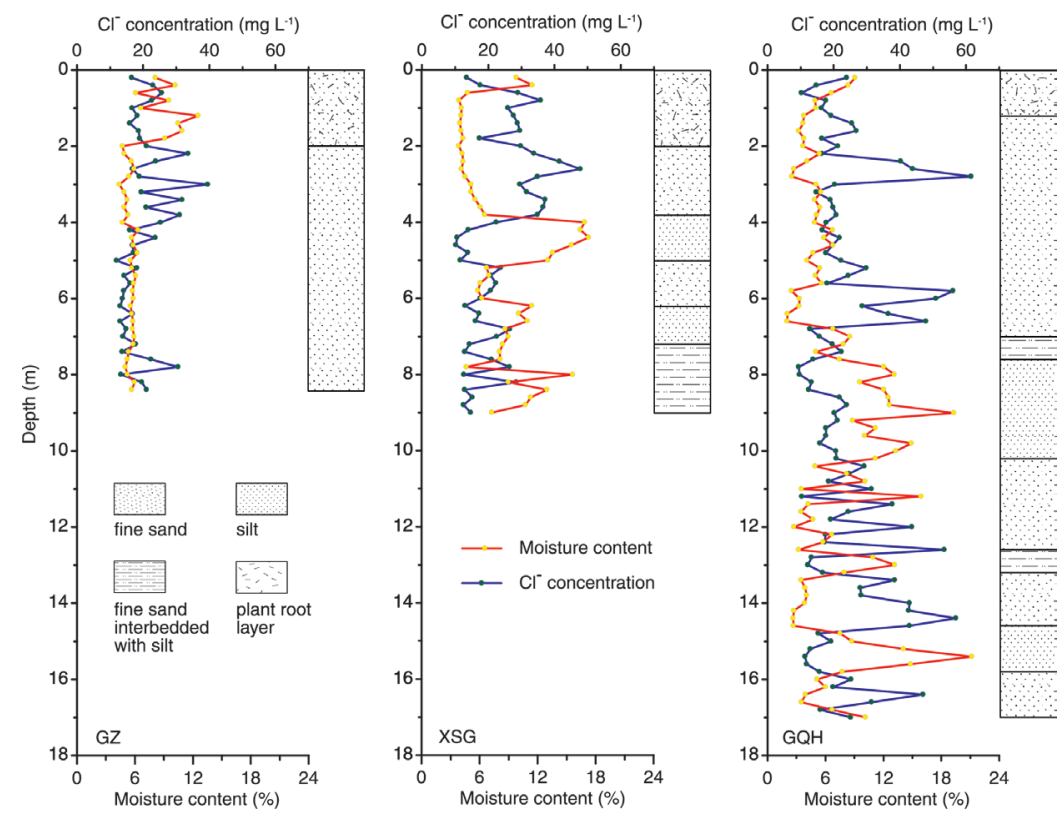

Fig. 2. The moisture content and $\mathrm{Cl}^{-}$concentration profiles for Gou-zhang (GZ), Ge-qiu-he (GQH), and Xia-sha-gou (XSG) sections . 
conducted on these sampling sites. The natural vegetation includes small shrubs and grasses (primarily Artemisia sphaerocephala and Astragalus adsurgens Pall) which, based on preliminary field reconnaissance, occur in densities typically less than 1 plant $\mathrm{m}^{-2}$.

All three cores were sampled at intervals of $0.2 \mathrm{~m}$. Homogenized bulk sediment samples over the sampling depth were immediately placed and sealed in air-tight polyethylene bags to minimize evaporation. The sample moisture contents were determined gravimetrically after drying for $24 \mathrm{~h}$ at $110^{\circ} \mathrm{C}$. Approximately $30 \mathrm{ml}$ deionized water was added to $50 \mathrm{~g}$ of the sediment sample in bakers for the chloride concentration. The mixture was stirred fully and then centrifuged at $2500 \mathrm{rpm}$ for $30 \mathrm{~min}$ to separate the water from sediment. The supernatant was filtered through $0.45(\mu \mathrm{m})$ filters and analyzed using ion chromatography (Dionex 600) for $\mathrm{Cl}^{-}$ concentrations at Institute of Earth Environment, Chinese Academy of Sciences. $\pm 3 \%$ of concentration was the analytical precision and $0.1 \mathrm{mg} \mathrm{L}^{-1}$ was the detection limit.

\section{METHODS FOR RECHARGE AND CHRONOLOGY CALCULATION AND CHLORIDE INPUT}

In the CMB method the following assumptions must be satisfied (Tyler et al. 1996; Ma and Edmunds 2006; Gates et al. 2008; Scanlon et al. 2010). The water recharge is solely from precipitation without the influence of run-on and runoff. Wet and dry deposition from the atmosphere is the only source of $\mathrm{Cl}^{-}$input in the soil water. The chloride concentration in precipitation is assumed constant over time represented by the mean available rainfall sample concentration. The annual chloride wet input is then assumed constant if the long-term average precipitation is adopted. Water percolation can be simplified as the one-dimensional, downward piston-type. With these assumptions, according to the mass balance theory, the $\mathrm{Cl}^{-}$mass from precipitation and dry fallout is considered unchanged during its subsurface transport with infiltrating water. When the percolating water undergoes evapotranspiration, the chloride is left while the moisture is reduced. As a result the $\mathrm{Cl}^{-}$concentrations are inversely proportional to the recharge rates (Allison and Hughes 1978; Edmunds et al. 1988):

$R=q_{c l} / C l_{s w}=\left(P C l_{p}+D\right) / C l_{s w}$

Where $R$ is the groundwater recharge $\left(\mathrm{LT}^{-1}\right) ; q_{c l}$ is the chloride deposited annually $\left(\mathrm{ML}^{-2} \mathrm{~T}^{-1}\right), P$ is precipitation $\left(\mathrm{LT}^{-1}\right)$, $C l_{p}$ is the chloride concentration in precipitation $\left(\mathrm{ML}^{-3}\right), D$ is dry deposition of $\mathrm{Cl}^{-}\left(\mathrm{ML}^{-2} \mathrm{~T}^{-1}\right)$, and $C l_{s w}$ is the chloride concentration in soil water $\left(\mathrm{ML}^{-3}\right) \cdot t_{x}(\mathrm{~T})$, the residence time of water at a given depth can be calculated by dividing the cumulative mass of chloride $(M)\left(\mathrm{ML}^{-2}\right)$ by the annual deposition flux of chloride mass $\left(q_{c l}\right)$ (Tyler et al. 1996):
$t_{x}=\frac{M}{q_{c l}}=\frac{\int_{0}^{x} \theta(x) C l_{s w}(x) d x}{q_{c l}}$

where $C l_{s w}(x)$ is the chloride concentration in soil water at a given depth $x\left(\mathrm{ML}^{-3}\right), \theta(x)$ is the volumetric water content at a given depth $x\left(\mathrm{~L}^{3} \mathrm{~L}^{-3}\right)$.

The chloride input is assumed to be constant over a long period in CMB. However, in the GCMB method, which was developed from the CMB method, variations in precipitation and chloride input are taken into account (Ginn and Murphy 1997):

$R\left[x, t_{0}(x)\right]=q_{0}\left[t_{0}(x)\right] / C l_{s w}(x)$

The residence time of water in the chloride profile can also be estimated (Ginn and Murphy 1997):

$\int_{0}^{x} \theta(x) C l_{s w}(x) d x=\int_{t_{0}(x)}^{t_{\text {now }}} q_{0}(t) d t$

where $t_{0}(x)$ is the entry time of an element in water at depth $x(\mathrm{~T}), t_{\text {now }}$ is the entry time of water currently at the surface $(\mathrm{T}), t_{\text {now }}-t_{0}(x)$ is the residence time, $q_{0}(t)$ is the transient chloride mass deposited $\left(\mathrm{ML}^{-2} \mathrm{~T}^{-1}\right), R\left[x, t_{0}(x)\right]$ and $q_{0}\left[t_{0}(x)\right]$ are the transient recharge rate and chloride influx, respectively $\left(\mathrm{L} \mathrm{T}^{-1}\right)\left(\mathrm{ML}^{-2} \mathrm{~T}^{-1}\right)$.

In order to estimate recharge rate using the $\mathrm{CMB} /$ GCMB methods, it is crucial to determine the chloride input. In the study area a seawater source is absent and the rock salt chloride contribution from silica sandy systems is also insignificant. The major chloride source in the profiles is from atmospheric deposition. The chloride input from the atmospheric source is also inevitably assumed constant over long time periods in the CMB method. As mentioned in the GCMB method the annual chloride input from the atmosphere, including wet and dry deposition is actually variable. Therefore, estimating the wet and $\mathrm{dry}^{-\mathrm{Cl}^{-}}$deposition in the study area is prerequisite.

It has been suggested that monitoring the rainfall chloride input for a minimum of 3 years is necessary for reliable wet deposition estimates (Sukhija et al. 1988; Edmunds and Gaye 1994; Bromley et al. 1997). The wet chloride input in this study refers to the value used by other researchers in nearby areas because long-term rainfall chemistry monitoring was unavailable in the study area. There were two groups of long-term rainfall chloride deposition monitoring near the study sites. The first is from the Badan Jaran Desert, about $400 \mathrm{~km}$ west of the study area, where the best rainfall $\mathrm{Cl}^{-}$deposition estimate was $1.5 \mathrm{mg} \mathrm{L}^{-1}$ based on three years monitoring (Ma and Edmunds 2006; Gates et al. 2008). The second monitoring source is from a rural monitoring station in the vicinity of Xi'an City (more than $500 \mathrm{~km}$ south of the study area) where the volume-weighted average chloride 
concentration was $1.7 \mathrm{mg} \mathrm{L}^{-1}$ according to 7-year monitoring from 2001 - 2007 (EANET 2009; Huang and Pang 2011). Here, we adopted the $1.5 \mathrm{mg} \mathrm{L}^{-1}$ value from Badan Jaran Desert as the $\mathrm{Cl}^{-}$rainfall concentration (i.e., wet deposition) since it is closer to the study sites and has similar climatic and environmental conditions.

The relationship between dry deposition and wet or total deposition can be helpful for estimation if the wet deposition is known. According to Dettinger's study in the Great Basin of Nevada and Utah, the dry chloride deposition accounts for about 33\% of the total influx (Dettinger 1989). As suggested by Yin et al. (2010), without the observed relationship between dry deposition and wet or total deposition, it is probably acceptable to use the relationship reported at the Great Basin of Nevada and Utah in the Ordos Plateau (including the Loess Plateau and Mu Us Desert) because the climatic and geomorphologic conditions are similar at both places (Yin et al. 2010). Thus, the total chloride influx here was also considered approximately 1.5 times wet influx.

As the chloride concentration in precipitation at a specific site is governed mainly by the distance to its oceanic source, the chloride wet deposition should be linearly proportional to the precipitation if the precipitation source remains constant (Tyler et al. 1996). If $1.5 \mathrm{mg} \mathrm{L}^{-1}$ is adopted as the $\mathrm{Cl}^{-}$rainfall concentration in this area and the annual average precipitation is known, the total annual chloride input from the atmosphere, including that from dry deposition, can be calculated. With this assumption the effective precipitation percentage that becomes diffuse recharge, designated effective $\alpha\left(t_{0}\right)$, may be calculated using the rewritten Eq. (3) as follows:

$\alpha\left(t_{0}\right)=\frac{1.5 c_{0} p\left[t_{0}(x)\right]}{C l_{s w} p\left[t_{0}(x)\right]}=\frac{1.5 c_{0}}{C l_{s w}}$

where $p\left[t_{0}(x)\right]$ is the transient precipitation, $c_{0}$ is the chloride concentration in the influx precipitation at the time of $t_{0}(x)$, equal to the aforementioned $C l_{p}$ with the relative assumption adopted in this study, and 1.5 is the coefficient for wet chloride deposition conversion to total chloride deposition.

Transient recharge rates may be obtained based on Eq. (3) from the GCMB method. However, it should be noted that the $\mathrm{Cl}^{-}$concentrations in GCMB method profiles indicate $\alpha\left(t_{0}\right)$ but not the recharge rates. So $\alpha\left(t_{0}\right)$ is first calculated using Eq. (5) and the transient recharge rates can then be calculated by multiplying $\alpha\left(t_{0}\right)$ by the precipitation. The GCMB method provides a way to obtain recharge rate transient variations and then the relation between the precipitation and recharge may be established.

The recharge estimation and residence time is quite susceptible to the influence of uncertainties associated with the $\mathrm{Cl}^{-}$input and output and moisture and $\mathrm{Cl}^{-}$transport processes (Dettinger 1989; Ginn and Murphy 1997; Scanlon 2000).
For example, Eqs. (1) or (3) show that the recharge estimation varies linearly with the $\mathrm{Cl}^{-}$input and Eqs. (2) or (4) show that the residence time varies inversely with the $\mathrm{Cl}^{-}$ input. Given the scarcity of data on precipitation chemistry in the study area, a large source of uncertainty comes from the errors in estimating the average precipitation chloride concentration. Undoubtedly, more data on chloride deposition should reduce the recharge estimate uncertainties based on the proposed method and more emphasis should be placed on long-term chloride deposition monitoring in (semi-) arid regions worldwide (Edmunds and Tyler 2002; Scanlon et al. 2006).

\section{RESULTS AND DISCUSSION}

\subsection{Moisture Content and Chloride Profiles}

The variations in soil moisture content with depth for the three profiles were different (Fig. 2). The mean soilmoisture content for the GZ profile was $6.3 \%$, ranging from $4.4-12.6 \%$. The XSG profile had relatively higher soil water contents as a whole, with an average of $8.2 \%$. The maximum water content was $17.3 \%$ and the minimum $4.0 \%$. Compared to the GZ profile, more fluctuations occurred in the XSG profile moisture content. The average moisture content in the GQH profile was $6.9 \%$, which was similar to that of the GZ profile. But the magnitude of soil moisture content variations in this profile was much larger, varying from $2.0-21.18 \%$ due to the greater lithology variability than in the other two profiles.

The three profiles all exhibited significant fluctuations in chloride distributions with depth (Fig. 2). Especially obvious peaks in $\mathrm{Cl}^{-}$existed near surface, which were widespread in (semi-) arid areas as a result of solutes accumulation and moisture removal by evapotranspiration (Gates et al. 2008). The chloride concentrations of the GZ profile fluctuated within a range of $11.9-39.5 \mathrm{mg} \mathrm{L}^{-1}$ with an average of $19.8 \mathrm{mg} \mathrm{L}^{-1}$. The chloride concentration range for the XSG profile was from $10.3-47.8 \mathrm{mg} \mathrm{L}^{-1}$ and the average was $23.1 \mathrm{mg} \mathrm{L}^{-1}$. The chloride concentration variation amplitude in the GQH profile was relatively larger than that for the other two profiles, with a minimum of $9.7 \mathrm{mg} \mathrm{L}^{-1}$ and a maximum of $61.5 \mathrm{mg} \mathrm{L}^{-1}$. The mean value of $24.3 \mathrm{mg} \mathrm{L}^{-1}$ was similar to that of the other two profiles.

\subsection{Recharge History from the Chloride Profiles}

The chloride profile cannot directly reflect recharge rates in the GCMB method, which is different from that in CMB method, because the annual precipitation variations and associated chloride influxes are involved. Instead, effective $\alpha\left(t_{0}\right)$ is indicated by $\mathrm{Cl}^{-}$concentrations in the GCMB method as mentioned before, with an inverse relation to the $\mathrm{Cl}^{-}$concentrations according to Eq. (5).

Employing 2008 as the moisture entry time (same as the 
sampling time) on the top of these profiles, we calculated the residence times for these profiles, effective $\alpha\left(t_{0}\right)$ and corresponding mean recharge rates at annual timescales using the GCMB method and precipitation records from 1954 - 2008 in Yulin and Hengshan. Because the salt and water activities in the root zone are rapid and unstable, the $\mathrm{Cl}^{-}$in the root zone cannot reflect effective $\alpha\left(t_{0}\right)$. Here we discuss only the effective $\alpha\left(t_{0}\right)$ and recharge rates recorded in chloride profiles below the root zones, which can be identified in the field and confirmed by the chloride distribution profiles, although the results from the root zones are also illustrated in plots.

Table 1 shows that the average effective $\alpha\left(t_{0}\right)$ recorded in the three chloride profiles were quite similar, with values of $12.3,12.2$, and $11.5 \%$, respectively. So did the mean recharge rates from them. They were $43.7,43.5$, and $45.1 \mathrm{~mm} \mathrm{yr}^{-1}$, respectively. Since the three chloride profiles represented different residence times, the cumulative chloride content with depth against the cumulative moisture content at the same depth was plotted for better comparisons of effective $\alpha\left(t_{0}\right)$ from the three profiles (Fig. 3). The slope of each straight-line segment in this plot was the $1 / \mathrm{Cl}^{-}$for the corresponding depth interval, which indicates the average effective $\alpha\left(t_{0}\right)$ for a period. These plots also show the similarity in average effective $\alpha\left(t_{0}\right)$ of the three profiles. The GZ and GQH profiles, which were both located near Yulin City, have the quite similar effective $\alpha\left(t_{0}\right)$.
Recharge rates obtained in this study can be compared with results from the CMB or GCMB methods in other regions in the world with similar climates. The mean recharge rate in a previous recharge study in Cyprus by Edmunds and Walton (1980) was $50 \mathrm{~mm} \mathrm{yr}^{-1}$ and accounted for $12.5 \%$ of the mean annual precipitation of $400 \mathrm{~mm}$. The recharge estimates in Senegal from chloride profiles were $30 \mathrm{~mm} \mathrm{yr}^{-1}$ and nearly $10 \%$ of the mean annual precipitation of $290 \mathrm{~mm} \mathrm{yr}^{-1}$ (Gaye and Edmunds 1996). Our results in this study are analogous to those in similar regions globally.

For discussion on the variations in recharge, the $\mathrm{Cl}^{-}$ and moisture content depth profiles were transformed into recharge rate and effective $\alpha\left(t_{0}\right)$ time series based on the residence time from Table 1 (Fig. 4). The periods pertinent to the plant zone which are not applicable in Table 1 are not included in this discussion. As shown in Fig. 4 the GZ profile below the root zone archived effective $\alpha\left(t_{0}\right)$ and recharge rates for 11 years from 1990 - 2000. The maximum effective $\alpha\left(t_{0}\right)$ was $16.1 \%$ and the minimum was $8.1 \%$, with an average of $12.3 \%$. The recharge rates in this period lay between $24.6-73.2 \mathrm{~mm} \mathrm{yr}^{-1}$, with a mean recharge rate of $43.7 \mathrm{~mm} \mathrm{yr}^{-1}$. It is clear that recharges in the mid-1990s were relatively higher than in the late 1990s. In the XSG profile effective $\alpha\left(t_{0}\right)$ and recharge rates of 21 years from 1981 - 2001 were recorded below the root zone. The effective $\alpha\left(t_{0}\right)$ fell between $6.2-20.8 \%$, with an average of $12.2 \%$.

Table 1. Estimates of annual mean recharge and corresponding residence time from chloride profiles using the GCMB method.

\begin{tabular}{|c|c|c|c|c|c|}
\hline Sites & $\begin{array}{l}\text { Depth of profile } \\
\text { (m) }\end{array}$ & $\begin{array}{c}\text { Mean precipitation } \\
\left(\mathrm{mm} \mathrm{yr}^{-1}\right)\end{array}$ & $\begin{array}{c}\text { Mean recharge } \\
\left(\mathrm{mm} \mathrm{yr}^{-1}\right)\end{array}$ & $\begin{array}{l}\text { Residence time below } \\
\text { root zones (years) }\end{array}$ & $\begin{array}{c}\text { Average effective } \\
\alpha\left(t_{0}\right)(\%)\end{array}$ \\
\hline GZ & 8.4 & 397 & 43.7 & 10 & 12.3 \\
\hline XSG & 9 & 376 & 43.5 & 20 & 12.2 \\
\hline $\mathrm{GQH}$ & 17 & 397 & 45.1 & 36 & 11.5 \\
\hline
\end{tabular}

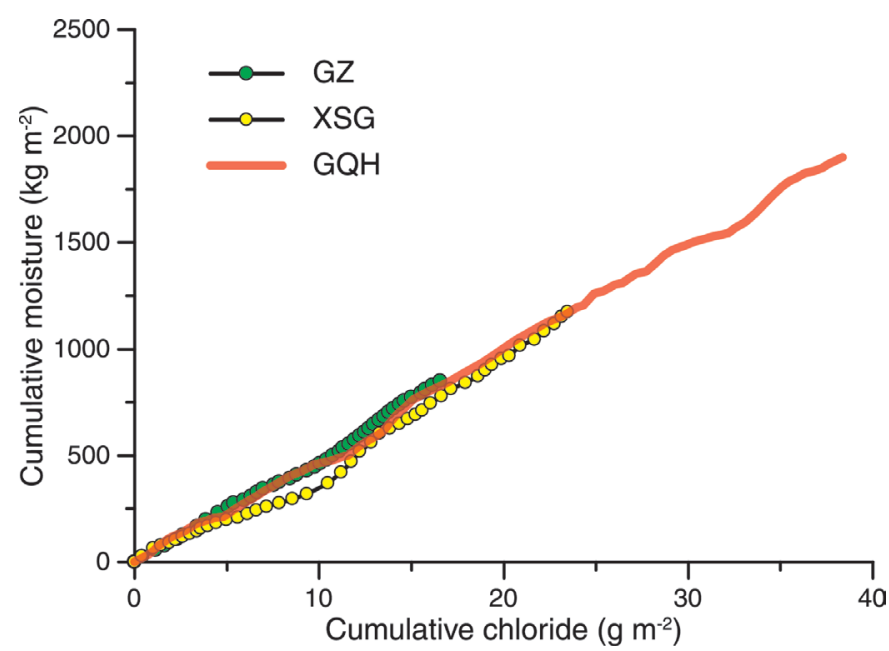

Fig. 3. Cumulative moisture vs. cumulative chloride of the three profiles. 


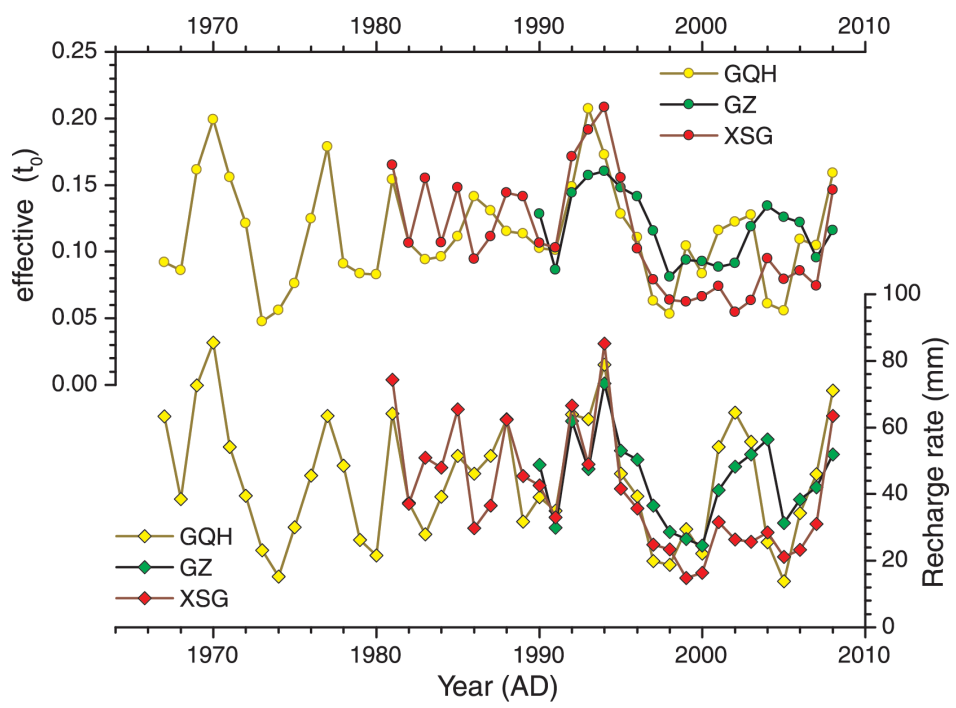

Fig. 4. Recharge history obtained from three chloride profiles.

The recharge rates ranged from $14.8-85.2 \mathrm{~mm} \mathrm{yr}^{-1}$, with an average of $43.5 \mathrm{~mm} \mathrm{yr}^{-1}$. Similar to the GZ profile the mid-1990s recharge was higher than that in other periods. The GQH profile recorded past recharge processes over a longer period because of its longer length. The 37-year recharge process from 1967 - 2003 was reconstructed based on chloride distribution below the root zone in the profile. During this period the average effective $\alpha\left(t_{0}\right)$ and recharge rate were $11.5 \%$ and $45.1 \mathrm{~mm} \mathrm{yr}^{-1}$, respectively, with the effective $\alpha\left(t_{0}\right)$ being in a range of $5-20.7 \%$ and recharge rates in a range of $15.2-85.5 \mathrm{~mm} \mathrm{yr}^{-1}$. The recharge was relatively high in the mid-1990s and late 1960s, but it was low in the early 1970s and late 1990s. The recharge variations during the 1990s in the GQH profile are similar to the former two profiles, indicating a consistent variation in recharges in the study region.

\subsection{Influence of Precipitation on Recharge}

Annual variations in recharge rates in the past obtained using the GCMB method make it possible to discuss the relationship between recharge and climate variables. Precipitation is one of the most important factors that affect groundwater recharge. In order to find annual precipitation and recharge trends the Mann-Kendall method for trend analysis was used (Burn and Elnur 2002; Kahya and Kalayci 2004). From 1967 - 2000 (with data counts of $n=34$ ), the MannKendall method $\mathrm{z}$ value for the yearly precipitation series was -2.11 , which suggested a significant descending trend with a confidence probability of $95 \%$. A descending trend in the annual recharge rate series is present for the $\mathrm{GQH}$ profile from 1967 - 2000 with a $\mathrm{z}$ value of -1.13 . Its descending trend was not significant even if it was on a confidence probability of $90 \%$. Although both yearly precipitation series and recharge series in this period displayed descending trends on the whole, there was a difference in the trend significance (Fig. 4). As shown in Fig. 5 the annual recharge rate was not completely in linear proportion to the corresponding annual precipitation. This implies that other factors besides the annual precipitation may influence the recharge as well.

Ginn and Murphy (1997) pointed out that such factors as an unknown nonlinear relationship between precipitation and recharge or ecosystem stress induced by climatic changes may result in the changes in effective $\alpha\left(t_{0}\right)$. In the study areas the majority of rainfall comes from storms and these storms yield major contributions to diffuse recharge (He and Liu 1996). Experiments on rainfall infiltration and evaporation were carried out in the Mu Us Desert. The results showed that precipitation infiltration in this area was closely related to the amount of rainfall at one time (Yuan et al. 2008). Most of the water from low daily precipitation may be consumed in evapotranspiration or just enough to wet the foliage and soil and thus they contribute no water to diffuse recharge. Therefore, it is likely that only daily rainfall above some certain amount can be conducive to infiltration.

Since the GZ and GQH profiles are both located in Yulin and the latter one kept recharge history over a relatively longer period, we investigated in detail the recharge rate and effective $\alpha\left(t_{0}\right)$ for these two profiles and their relations to daily Yulin precipitation characteristics in the corresponding years. Based on daily metrological records the daily Yulin precipitation characteristics were analyzed by aggregating the daily precipitation over a given interval. The daily precipitation sum equal and above $50 \mathrm{~mm}$, that equal and above $30 \mathrm{~mm}$ but below $50 \mathrm{~mm}$, that equal and above $13 \mathrm{~mm}$ but below $30 \mathrm{~mm}$, that equal and above $5 \mathrm{~mm}$ but below $13 \mathrm{~mm}$, and that below $5 \mathrm{~mm}$ were calculated, respectively. The daily precipitation aggregate over the given intervals listed above 
in each year were represented by different shades as shown in Fig. 5. It shows that there was no absolute coincidence between the annual precipitation and heavy rain occurrences in a year. That means in some years the annual precipitation was not high in spite of the fact that much more heavy rain occurred in that year, for instance in the early 1970s.

The comparison of annual recharge and daily precipitation aggregate indicates that during some periods, as indicated by the light grey bars in Fig. 5, the annual recharge presented an exceptionally opposite trend to the annual precipitation. In years from 1992 - 1995, for example, the recharge rates were rather high while the annual precipitations were not so high. However, as shown in Fig. 5, it is evident that daily precipitation equal and above $30 \mathrm{~mm}$ in these years occurred more frequently and this portion of the precipitation in each year accounted for a majority of the yearly precipitation. Similarly, during the period from 1969 - 1971, the effective $\alpha\left(t_{0}\right)$ and recharge rates were rather high compared to the annual precipitation for the period. It may also be attributed to the fact that heavy daily precipitation occurred much more during these years, especially storms with daily precipitation equal and above $50 \mathrm{~mm}$. Such phenomenon could be found during the mid-1970s, from 1975 - 1977 as well, although the discrepancy between the annual precipitation and recharge rates in value was not as prominent as in the periods mentioned above.

Very low daily precipitations may contribute no infiltration to groundwater. This was experimentally tested in a previous study by Yuan et al. (2008). They discovered that daily precipitation below $15 \mathrm{~mm}$ could not produce diffuse recharge in the study area. Similar phenomena can also be identified in our study as shown in Fig. 5 with dark grey bars. For example, in years of 1974, 1980, 1983, 1989, and 1998, the effective $\alpha\left(t_{0}\right)$ and recharge rates were rather low. This may result from the low annual precipitation accompanied by rare daily precipitation above $30 \mathrm{~mm}$. Lack of storms may make the diffuse recharge decrease considerably. It can be inferred that recharge can be negligible in some particular years when even daily rainfall events with precipitation above $13 \mathrm{~mm}$ seldom took place. The year 1965 might be such a year although the recharge history in this study was not long enough to cover it. All of these comparisons suggest that daily precipitation characteristics in each year have substantial influences on the annual recharge and should be taken into account in recharge estimation.

Besides the direct impact of precipitation on the groundwater recharge, the possible effect of successive droughts on the vegetation cover and thus on recharge changes was also mentioned in the study of Ginn and Murphy (1997). Reduced vegetative cover after several drought years may

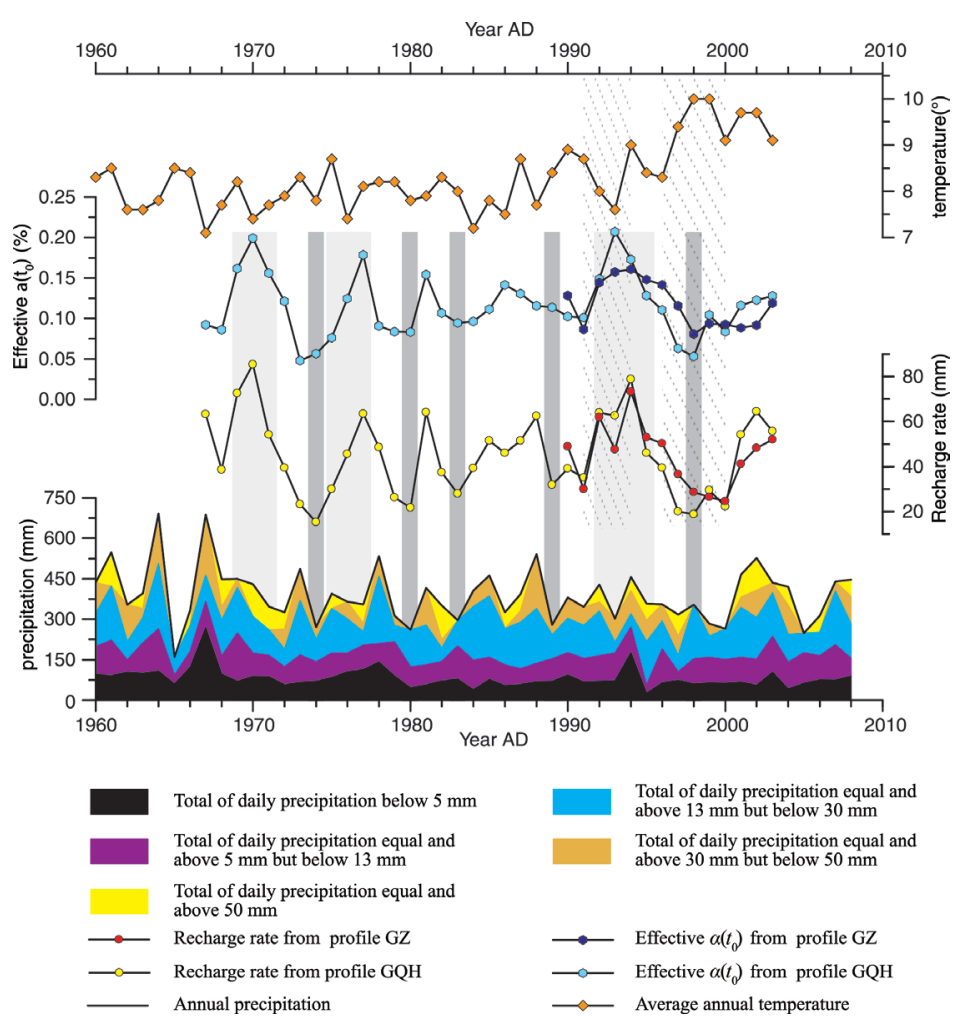

Fig. 5. Variations in effective $\alpha\left(t_{0}\right)$ and recharge rates from Gou-zhang (GZ) and Ge-qiu-he (GQH) profiles compared with those of annual precipitation and average annual temperature. Vertical grey bars were used to emphasize the typical durations in which the influence of precipitation on recharge was discussed in the main text. Dashed lines were used to indicate the periods in which the temperature influence on recharge was discussed in the main text. The recharge duration after 2003 corresponding to the plant zone section was blocked because it has no meaning for discussion. 
result in decreased water uptake by vegetation and then a greater recharge per annual precipitation would take place in the following years. In this case the substantial increase in recharge from 1992 - 1996 may also be partially attributed to the vegetation decrease on the land surface following successive relative droughts in the three years before 1992. The influence of vegetative cover change on recharge is the indirect result of precipitation variations. Therefore, precipitation changes may influence groundwater recharge in both direct and indirect ways.

\subsection{Influence of Temperature on Recharge}

As one of the most important factors controlling evapotransporation, temperature also has some substantial impacts on soil moisture (Miralles et al. 2014). In Yulin the correlation coefficient between the average monthly evaporation and temperature comes to 0.91 (Wang 2006). Changes in average annual temperature may also be responsible for nonlinear annual recharge response to the annual precipitation. With respect to the influence of temperature on recharge, the two GZ and GQH chloride profiles are also inspected and discussed. The variation in temperature in the study area in Fig. 5 shows that the average annual temperature there steadily increased since the 1960s. Particularly after the 1990s the increasing temperature trend was rather prominent, coincident with global warming. Comparison between the annual effective $\alpha\left(t_{0}\right)$ and average annual temperature revealed an approximately negative correlation. A more notable correlation could be identified after the 1990s as the accelerated temperature increase occurred since. During a representative period, for example the late 1990s, shaded by dashed lines in Fig. 5, substantial increase in average annual temperature might result in exceptionally low annual effective $\alpha\left(t_{0}\right)$ in this period and thus very low recharge rates, even though heavy daily precipitation frequently occurred in some years. The similar negative correlation between the average annual temperature and effective $\alpha\left(t_{0}\right)$ was also noticeable in the years around 1993, as shaded by dashed lines, during which high annual effective $\alpha\left(t_{0}\right)$ and recharge rates corresponded to relatively low average annual temperature. Both the relatively low temperature and the heavy daily precipitations led to the remarkable high annual effective $\alpha\left(t_{0}\right)$ in this period. Investigating the relationship between temperature and recharge indicates that temperature variations may also disturb the linear annual recharge response to annual precipitation by its impacts on evapotranspiration.

\section{CONCLUSIONS}

Chloride profiles in semi-arid areas can maintain the historical recharge record with less compressed timescales. The GCMB method developed from the CMB method provides a way to reconstruct recharge history with higher reso- lution compared to the CMB method. With the aid of annual recharge time series and available daily meteorological data, it is possible for us to investigate the relationship between recharge and main climatic variables. In this study the recharge history on decadal time scale in the desert/loess transition zone of northwest China, a typically semi-arid area, was reconstructed from chloride profiles using the GCMB method. The results indicate that the average recharge rates for three chloride profiles, i.e., GZ, XSG, and GQH, were 43.7, 43.5, and $45.1 \mathrm{~mm} \mathrm{yr}^{-1}$, representing $12.3,12.2$, and $11.5 \%$ of the mean annual precipitation, respectively. Although the recharge records obtained from the three profiles cover different time periods, the recharge processes within overlapped time spans were quite similar. The recharge estimations are also analogous to those using the CMB or GCMB methods in other regions with similar climate conditions.

The significant changes in annual effective $\alpha\left(t_{0}\right)$ in this study indicate that a linear relationship between annual precipitation and recharge rate does not always exist, i.e., there are other climatic factors than annual total amount of rainfall exerting influence on the annual recharge. Comparisons between the daily precipitation at different intensity and recharge rates reveal that relatively heavy daily precipitation occurrences per year might be associated with such nonlinearity between the annual precipitation and recharge. On the one hand, in those years when relatively heavy daily precipitation occurred more frequently, exceptionally high annual recharge may take place, even if the annual total precipitation was not high. On the other hand, in those years when heavy daily precipitation rarely occurred, the annual recharge might be low even though the annual precipitation was high. Furthermore, the indirect influence of precipitation on recharge may also be responsible for such nonlinear relation, as precipitation anomalies in successive years may substantially affect recharge through changes in vegetation. In addition to precipitation, temperature is another important climate factor controlling recharge because of its impact on evapotranspiration. The approximately negative correlation between the average annual recharge and temperature indicates that the variation in mean annual temperature might also disturb the linear response of annual recharge to annual precipitation.

In conclusion, groundwater recharge is governed strongly and comprehensively by various climatic variables. With more frequent climate extremes occurring today, the influence of climate change on groundwater recharge should be better understood for sustainable development of groundwater resources in the study area.

Acknowledgements The authors would like to thank Dr. Zhang Haiwei and Prof. Zhang Hongbo for their assistance in field work and data analyses. The authors would also like to thank Prof. Chen Wenfu and the Anonymous Reviewer for their helpful comments and suggestions on improving this manuscript. This research is supported by the Open 
Foundation of State Key Laboratory of Loess and Quaternary Geology, Institute of Earth Environment, Chinese Academy of Sciences (SKLLQG0805).

\section{REFERENCES}

Ali, R., D. McFarlane, S. Varma, W. Dawes, I. Emelyanova, G. Hodgson, and S. Charles, 2012: Potential climate change impacts on groundwater resources of south-western Australia. J. Hydrol., 475, 456-472, doi: 10.1016/j.jhydrol.2012.04.043. [Link]

Allison, G. B. and M. W. Hughes, 1978: The use of environmental chloride and tritium to estimate total recharge to an unconfined aquifer. Aust. J. Soil Res., 16, 181195, doi: 10.1071/SR9780181. [Link]

Bromley, J., W. M. Edmunds, E. Fellman, J. Brouwer, S. R. Gaze, J. Sudlow, and J. D. Taupin, 1997: Estimation of rainfall inputs and direct recharge to the deep unsaturated zone of southern Niger using the chloride profile method. J. Hydrol., 188-189, 139-154, doi: 10.1016/ S0022-1694(96)03157-5. [Link]

Burn, D. H. and M. A. H. Elnur, 2002: Detection of hydrologic trends and variability. J. Hydrol., 255, 107-122, doi: 10.1016/S0022-1694(01)00514-5. [Link]

Chen, Z., E. Bi, Z. Nie, H. Ye, and Y. Nan, 2001: A tentative discussion on paleohydrological and paleoclimatical information from unsaturated zone profile. Acta Geoscientia Sin., 22, 335-339. (in Chinese)

Chen, Z., S. E. Grasby, and K. G. Osadetz, 2004: Relation between climate variability and groundwater levels in the upper carbonate aquifer, southern Manitoba, Canada. J. Hydrol., 290, 43-62, doi: 10.1016/j. jhydrol.2003.11.029. [Link]

Cook, P. G., W. M. Edmunds, and C. B. Gaye, 1992: Estimating paleorecharge and paleoclimate from unsaturated zone profiles. Water Resour. Res., 28, 2721-2731, doi: 10.1029/92WR01298. [Link]

De Vries, J. J. and I. Simmers, 2002: Groundwater recharge: An overview of processes and challenges. Hydrogeol. J., 10, 5-17, doi: 10.1007/s10040-001-0171-7. [Link]

De Vries, J. J., E. T. Selaolo, and H. E. Beekman, 2000: Groundwater recharge in the Kalahari, with reference to paleo-hydrologic conditions. J. Hydrol., 238, 110123, doi: 10.1016/S0022-1694(00)00325-5. [Link]

Dettinger, M. D.,1989: Reconnaissance estimates of natural recharge to desert basins in Nevada, U.S.A., by using chloride-balance calculations. J. Hydrol., 106, 55-78, doi: 10.1016/0022-1694(89)90166-2. [Link]

EANET, 2009: Data report on the acid deposition in the East Asian region 2008. EANET data on the Acid Deposition in the East Asian Region, Network Center for EANET, Acid Deposition Monitoring Network in East Asia. Available at http://www.eanet.asia/product/.

Edmunds, W. M. and N. R. G. Walton, 1980: A geochem- ica1 and isotopic approach to recharge evaluation in semi-arid zones, past and present. Arid-Zone Hydrology: Investigations with Isotope Techniques, Panel Proceedings Series, Vol. 547, International Atomic Energy Agency, Vienna, Austria, 47-68.

Edmunds, W. M. and C. B. Gaye, 1994: Estimating the spatial variability of groundwater recharge in the Sahel using chloride. J. Hydrol., 156, 47-59, doi: 10.1016/00221694(94)90070-1. [Link]

Edmunds, W. M. and S. W. Tyler, 2002: Unsaturated zones as archives of past climates: Toward a new proxy for continental regions. Hydrogeol. J., 10, 216-228, doi: 10.1007/s10040-001-0180-6. [Link]

Edmunds, W. M., W. G. Darling, and D. G. Kinniburgh, 1988: Solute Profile techniques for recharge estimation in semi-arid and arid terrain. In: Simmers, I. (Ed), Estimation of Natural Groundwater Recharge, NATO ASI Series, Vol. 222, Springer Netherlands, Netherlands, 139-157, doi: 10.1007/978-94-015-7780-9_9. [Link]

Edmunds, W. M., C. B. Gaye, and J. C. Fontes, 1992: A record of climatic and environmental change contained in interstitial waters from the unsaturated zone of northern Senegal. In: Isotope Techniques in Water Resources Development 1991, International Atomic Energy Agency, Vienna, Austria, 533-549.

Gates, J. B., W. M. Edmunds, J. Ma, and P. R. Sheppard, 2008: A 700-year history of groundwater recharge in the drylands of NW China. Holocene, 18, 1045-1054, doi: 10.1177/0959683608095575. [Link]

Gaye, C. B. and W. M. Edmunds, 1996: Intercomparison between physical, geochemical and isotopic methods for estimating groundwater recharge in northwestern Senegal. Environ. Geol., 27, 246-251.

Ginn, T. R. and E. M. Murphy, 1997: A transient flux model for convective infiltration: Forward and inverse solutions for chloride mass balance studies. Water Resour. Res., 33, 2065-2079, doi: 10.1029/97WR01618. [Link]

He, Q. and Z. Q. Liu, 1996: Mu Us Desert-the storm center of deserts in the world. Meteorol.J.Inner Mongolia, $\mathbf{3}$, 5-15. (in Chinese)

Hou, G., Y. Liang, L. Yin, Z. Tao, Z. Zhao, Y. Yang, and $X$. Wang, 2009: Groundwater systems and water resources potential in the Ordos Basin. Hydrogeol. Eng. Geol., 36, 18-23. (in Chinese)

Huang, T. and Z. Pang, 2011: Estimating groundwater recharge following land-use change using chloride mass balance of soil profiles: A case study at Guyuan and Xifeng in the Loess Plateau of China. Hydrogeol. J., 19, 177-186, doi: 10.1007/s10040-010-0643-8. [Link]

Jyrkama, M. I. and J. F. Sykes, 2007: The impact of climate change on spatially varying groundwater recharge in the grand river watershed (Ontario). J. Hydrol., 338, 237-250, doi: 10.1016/j.jhydrol.2007.02.036. [Link]

Kahya, E. and S. Kalayci, 2004: Trend analysis of streamflow 
in Turkey. J. Hydrol., 289, 128-144, doi: 10.1016/j.jhydrol.2003.11.006. [Link]

Lin, D., M. Jin, X. Liang, and H. Zhan, 2013: Estimating groundwater recharge beneath irrigated farmland using environmental tracers fluoride, chloride and sulfate. Hydrogeol. J., 21, 1469-1480, doi: 10.1007/s10040013-1015-y. [Link]

Lin, R. and K. Wei, 2001: Environmental isotope profiles of the soil water in loess unsaturated zone in semi-arid areas of China. Isotope Based Assessment of Groundwater Renewal in Water Scarce Regions, International Atomic Energy Agency, Vienna, 101-118.

Liu, J., Z. Chen, Z. Zhang, Y. Fei, F. Zhang, J. Chen, and Z. Wang, 2009: Estimation of natural groundwater recharge in the Hutuo River alluvial-proluvial fan using environmental tracers. Geol. Sci. Tech. Inform., 28, 114-118, doi: 10.3969/j.issn.1000-7849.2009.06.018. (in Chinese) [Link]

Ma, J. and W. M. Edmunds, 2006: Groundwater and lake evolution in the Badain Jaran Desert ecosystem, Inner Mongolia. Hydrogeol. J., 14, 1231-1243, doi: 10.1007/ s10040-006-0045-0. [Link]

Ma, J., W. M. Edmunds, J. He, and B. Jia, 2009: A 2000 year geochemical record of palaeoclimate and hydrology derived from dune sand moisture. Palaeogeogr. $\mathrm{Pa}$ laeoclimatol. Palaeoecol., 276, 38-46, doi: 10.1016/j. palaeo.2009.02.028. [Link]

Miralles, D. G., A. J. Teuling, C. C. van Heerwaarden, and J. V.G. de Arellano, 2014: Mega-heatwave temperatures due to combined soil desiccation and atmospheric heat accumulation. Nat. Geosci., 7, 345-349, doi: 10.1038/ ngeo2141. [Link]

Murphy, E. M., T. R. Ginn, and J. L. Phillips, 1996: Geochemical estimates of paleorecharge in the Pasco Basin: Evaluation of the chloride mass balance technique. Water Resour. Res., 32, 2853-2868, doi: 10.1029/96WR01529. [Link]

Ng, G. H. C., D. McLaughlin, D. Entekhabi, and B. Scanlon, 2009: Using data assimilation to identify diffuse recharge mechanisms from chemical and physical data in the unsaturated zone. Water Resour. Res., 45, W09409, doi: 10.1029/2009WR007831. [Link]

Scanlon, B. R., 1991: Evaluation of moisture flux from chloride data in desert soils. J. Hydrol., 128, 137-156, doi: 10.1016/0022-1694(91)90135-5. [Link]

Scanlon, B. R., 2000: Uncertainties in estimating water fluxes and residence times using environmental tracers in an arid unsaturated zone. Water Resour. Res., 36, 395-409, doi: 10.1029/1999WR900240. [Link]

Scanlon, B. R., K. E. Keese, A. L. Flint, L. E. Flint, C. B.
Gaye, W. M. Edmunds, and I. Simmers, 2006: Global synthesis of groundwater recharge in semiarid and arid regions. Hydrol.Process., 20, 3335-3370, doi: 10.1002/ hyp.6335. [Link]

Scanlon, B. R., A. Mukherjee, J. Gates, R. C. Reedy, and A. K. Sinha, 2010: Groundwater recharge in natural dune systems and agricultural ecosystems in the Thar Desert region, Rajasthan, India. Hydrogeol. J., 18, 959-972, doi: 10.1007/s10040-009-0555-7. [Link]

Stone, W. J., 1992: Paleohydrologic implications of some deep soilwater chloride profiles, Murray Basin, South Australia. J. Hydrol., 132, 201-223, doi: 10.1016/00221694(92)90179-Y. [Link]

Sukhija, B. S., D. V. Reddy, P. Nagabhushanam, and R. Chand, 1988: Validity of the environmental chloride method for recharge evaluation of coastal aquifers, India. J. Hydrol., 99, 349-366, doi: 10.1016/0022-1694(88)90058-3. [Link]

Tyler, S. W., J. B. Chapman, S. H. Conrad, D. P. Hammermeister, D. O. Blout, J. J. Miller, M. J. Sully, and J. M. Ginanni, 1996: Soil-water flux in the southern Great Basin, United States: Temporal and spatial variations over the last 120,000 years. Water Resour. Res., 32, 1481-1499, doi: 10.1029/96WR00564. [Link]

Wang, B., M. Jin, W. Wang, and L. Yang, 2006: Application of chloride ion tracer method in estimation of vertical infiltration recharge of groundwater in Hebei plain. Water Saving Irrig., 3, 16-20. (in Chinese)

Wang, G. Q., 2006: Impacts of climate change on hydrology and water resources in middle reaches of the Yellow River basin. Ph.D. Thesis, Hohai University, Nanjing, 109 pp. (in Chinese)

Wang, Y. L., W. K. Wang, H. Zhang, Y. Li, Z. Y. Yang, and L. Duan, 2008: Ecology-oriented groundwater sustainable exploration plan in the wind-blown sand beach area north Shaanxi, China. Geol. Bull. China, 27, 1323-1329. (in Chinese)

Yin, L., G. Hou, Z. Tao, and Y. Li, 2010: Origin and recharge estimates of groundwater in the ordos plateau, People's Republic of China. Environ. Earth Sci., 60, 1731-1738, doi: 10.1007/s12665-009-0310-3. [Link]

Yuan, P., G. Ding, W. Wang, X. Wang, and H. Shi, 2008: Characteristics of rainwater infiltration and evaporation in Mu Us sandland. Sci. Soil Water Conserv., 6, 23-27. (in Chinese)

Zhang, L., L. Yue, and B. Xia, 2003: The study of land desertification in transitional zones between the MU US Desert and the Loess Plateau using RS and GIS-a case study of the Yulin region. Environ. Geol., 44, 530-534, doi: 10.1007/s00254-003-0788-z. [Link] 